\title{
Olfactory Discrimination Learning Increases the Survival of Adult-Born Neurons in the Olfactory Bulb
}

\author{
Mariana Alonso, ${ }^{1 \star}$ Cécile Viollet, ${ }^{1 \star}$ Marie-Madeleine Gabellec, ${ }^{1}$ Vannary Meas-Yedid, ${ }^{2}$ Jean-Christophe Olivo-Marin, ${ }^{2}$ \\ and Pierre-Marie Lledo ${ }^{1}$ \\ ${ }^{1}$ Perception and Memory Laboratory, Centre National de la Recherche Scientifique, Unité de Recherche Associée 2182, and ${ }^{2}$ Quantitative Image Analysis \\ Unit, Centre National de la Recherche Scientifique, Unité de Recherche Associée 2582, Pasteur Institute, 75724 Paris Cedex 15, France
}

In the olfactory bulb $(\mathrm{OB})$, new neurons are added throughout life, forming an integral part of the functioning circuit. Yet only some of them survive more than a month. To determine whether this turnover depends on olfactory learning, we examined the survival of adult newborn cells labeled with the cell division marker BrdU, administered before learning in an olfactory discrimination task. We report that discrimination learning increases the number of newborn neurons in the adult OB by prolonging their survival. Simple exposure to the pair of olfactory cues did not alter neurogenesis, indicating that the mere activation of sensory inputs during the learning task was insufficient to alter neurogenesis. The increase in cell survival after learning was not uniformly distributed throughout angular sectors of coronal sections of the OB. Monitoring odor activation maps using patterns of Zif268 immediate early gene expression revealed that survival was greater in regions more activated by the non-reinforced odorant. We conclude that sensory activation in a learning context not only controls the total number of newborn neurons in the adult OB, but also refines their precise location. Shaping the distribution of newborn neurons by influencing their survival could optimize the olfactory information processing required for odor discrimination.

Key words: neurogenesis; experience; interneurons; sensory map; plasticity; MOR23

\section{Introduction}

Newborn neurons continue to be added to some regions of the adult nervous system (Ming and Song, 2005; Lledo et al., 2006), with the hippocampal dentate gyrus and the olfactory bulb (OB) representing the two most characterized networks that continuously integrate large numbers of newborn neurons during adult life (Alvarez-Buylla and Garcia-Verdugo, 2002; Kempermann et al., 2004). In the OB, the newcomers originate from the periventricular region, migrate along the rostral migratory stream (RMS), and differentiate into local interneurons (i.e., granule cells or periglomerular cells), before integrating into functional circuitry (Belluzzi et al., 2003; Carleton et al., 2003). It is believed that the recruitment of new neurons into adult circuits belongs to a large repertoire of neuroadaptative responses (Abrous et al., 2005) that tightly depend on overall neuronal activity. We now know that recruitment of newborn neurons into bulbar circuits

Received June 22, 2006; revised Aug. 3, 2006; accepted Aug. 24, 2006.

This work was supported by the Pasteur Institute (Grand Programme Horizontal number 7), the Fondation pour la Recherche Médicale (M.A.), a grant from Région Ile-de-France to M.A., the Fédération pour la Recherche sur le Cerveau, Agence Nationale de la Recherche Grant ANR-05-Neur-028-01, and Institut National de la Santé et de la Recherche Médicale: Adult Stem Cells CS0303. We thank M. Grubb for insightful comments on the manuscript, A. Vassalli and P. Mombaerts for providing transgenic animals, C. Kielar for participating in preliminary experiments, and the Plate-Forme d'Imagerie Dynamique for technical assistance with confocal microscopy.

*M.A and C.V. contributed equally to this work.

Correspondence should be addressed to Pierre-Marie Lledo, Pasteur Institute, Laboratory of Perception and Memory, Centre National de la Recherche Scientifique, Unité de Recherche Associée 2182, 25 rue du Dr. Roux, 75724 Paris Cedex 15, France. E-mail: pmlledo@pasteur.fr.

Cecile Viollet's present address: Institut National de la Santé et de la Recherche Médicale (INSERM), U549 Paris, France.

DOI:10.1523/JNEUROSCI.2633-06.2006

Copyright $\odot 2006$ Society for Neuroscience $\quad 0270-6474 / 06 / 2610508-06 \$ 15.00 / 0$ closely correlates with the complexity of the olfactory environment (Petreanu and Alvarez-Buylla, 2002; Rochefort et al., 2002) and that their survival tightly depends on the sensory experience occurring during a precise critical period (Yamaguchi and Mori, 2005). Yet, the way new neurons are locally selected to integrate and survive in the appropriate microcircuit remains unknown, and today, understanding the functional meaning of this phenomenon represents one of the major challenges.

Learning may be a situation in which the integration of newborn neurons might be specifically tuned. We investigated this hypothesis by asking, first, if an olfactory discrimination task could regulate newborn neuron survival in the $\mathrm{OB}$, and second, if the location where newborn neurons survive coincides with the position of the host microcircuit relevant to the learning process. We took advantage of genetically engineered mice in which a single glomerulus was reliably identified, to investigate the precise topographical distribution of new neurons after an associative olfactory learning task. Unexpectedly, we found not only that the spatial distribution of the newcomers was sensitive to a learning experience lasting only $6 \mathrm{~d}$, but also that survival was increased in circuits that showed the greatest difference in activation in favor of the non-reinforced olfactory cue.

\section{Materials and Methods}

Mice. Two- to three-month-old mouse odorant receptor gene number 23 (MOR23)-green fluorescent protein (GFP) mice (Vassalli et al., 2002) were used throughout this study (see Fig. 1A). All experiments were performed by procedures approved by our local experimental animal research committee.

BrdU injections. Mice were injected intraperitoneally with BrdU (100 
$\mathrm{mg} / \mathrm{kg}$ ) every $2 \mathrm{~h}$, repeated six times on a single day, and perfused 15 or 30 d later. Female littermates constituted naive BrdU-injected controls in each behavioral experiment. There was no significant gender effect on newborn neuron survival (data not shown).

Behavioral apparatus. Odors were presented on sponge rings $(1 \mathrm{~cm}$ wide, $2 \mathrm{~mm}$ thick) inserted around transparent plastic tubes $(2.5 \mathrm{~cm}$ diameter, $3 \mathrm{~cm}$ width) filled with fresh bedding shavings. Each sponge was impregnated with $60 \mu \mathrm{l}$ of odorant. The odorants used were lyral (International Flavors and Fragrances, New York, NY) and acetophenone (Sigma, St. Louis, MO). Odorless mineral oil (MO; Sigma) was used as a control. Training took place in a box $(50 \times 50 \times 50 \mathrm{~cm})$, in which the tubes were inserted $15 \mathrm{~cm}$ apart from each other, sponges laying on the box floor. Behavioral recording was performed blindly to odor location and experimental status of the animal. New sets of sponges and tubes were used for each trial to preclude any contaminating odorant cues, and positions of each odorant and reward were randomized throughout training.

Spontaneous odor exploration. One day after a $5 \mathrm{~min}$ shaping session performed in the absence of odorant cues, mice were exposed to one odorant versus MO for $5 \mathrm{~min}$. The time spent by the animal sniffing at each sponge was measured.

Olfactory discrimination training. Isolated and mildly food-deprived male mice ( $85 \%$ of their initial weight) were submitted to two shaping sessions (one session per day, six trials per session, 15 min intertrial interval), during which animals learned to find, in the absence of any odorant cues, a food reward (a piece of cereal) randomly hidden in the bedding shavings. Mice were then subjected to a discrimination learning between lyral (pure) and acetophenone $\left(10^{-3} \mathrm{v} / \mathrm{v}\right.$ in MO) during six consecutive days (one session per day, six trials per session, $15 \mathrm{~min}$ intertrial interval). These concentrations were chosen because mice explored them equally (see Fig. 2C), showing no systematic aversion or attraction effects. Two experimental groups were defined: a paired group in which the reward was always buried in the tube odorized with lyral, and an unpaired group, in which the reward was randomly associated with either odorant. Mice were allowed to find the reward for a maximal time of $90 \mathrm{~s}$, and were put back in their home cage as soon as they had eaten it. The percentage of first correct responses (i.e., first digging in rewarded tube) for each daily session was assessed. Three independent experiments were performed. BrdU-injected littermates were used to determine the levels of BrdU incorporation in basal (control group) or isolated and food-restricted conditions (deprived group; handled daily for 8 d) (supplemental Fig. 2, available at www.jneurosci.org as supplemental material). All animals were perfused $30 \mathrm{~d}$ after BrdU injection.

Olfactory stimulation. Mice were exposed to deodorized air $(1950 \mathrm{cc} /$ $\mathrm{min}$ ) for $30 \mathrm{~min}$ for 2 successive days in the clear box of an air dilution olfactometer (Knosys Olfactometers, Bethesda, MD). A shaping session aimed at habituating the animal to experimental nonolfactory changes was performed with deodorized air applied for $15 \mathrm{~min}$, then the valves of the gas-mixing flow-meter were successively opened and closed twice for $5 \mathrm{~min}$ each, mimicking air fluxes. The following day, mice were subjected to (1) deodorized air for $30 \mathrm{~min}$, (2) odorant-containing air (2.5\% dilution) for $5 \mathrm{~min}$ followed by $5 \mathrm{~min}$ application of deodorized air, three times, and (3) deodorized air for $1 \mathrm{~h}$ (adapted from Inaki et al., 2002), and then mice were quickly perfused. Odors used were acetophenone $\left(10^{-3} \mathrm{v} / \mathrm{v}\right.$ in $\left.\mathrm{MO}\right)$ and lyral (pure), and pure MO was used to determine basal levels of Zif268 expression.

Immunohistochemistry. Forty-micrometer-thick coronal OB sections containing at least part of the medial MOR23-GFP-labeled glomerulus were selected under a fluorescent stereomicroscope to be processed for GFP/BrdU or GFP/Zif268 double staining using the ABC system (Vector Laboratories, Burlingame, CA) with different chromogens, or for BrdU/ NeuN double fluorescence staining. Primary antibodies used were rabbit anti-GFP polyclonal (Invitrogen, Eugene, OR), rat anti-BrdU (Oxford Biotech, Kidlington, UK), rabbit anti-Zif268 (anti-Egr-1, Santa Cruz Biotechnology, Santa Cruz, CA) or mouse anti-NeuN (Chemicon, Temecula, CA) antibodies, whereas secondary antibodies were speciesrespective (Vector Laboratories; Invitrogen) (see also supplemental methods, available at www.jneurosci.org as supplemental material).

Cell counting by image analysis. Slides were blind coded until comple- tion of the data analysis. On $20 \times$-objective reconstructed images of each section (Compix Imaging; Hamamatsu Photonics, Massy, France), $\mathrm{BrdU}^{+}$and $\mathrm{Zif} 268^{+}$cells were automatically counted by a dedicated stereological computer program (Olivo-Marin, 2002). After the interactive drawing of both internal and external borders of the glomerular (GL) and granule cell (GCL) layers, the MOR23 axis was defined as going from the center of the glomerulus through the center of mass of the RMS (Fig. $3 A, B)$. The program then numbered cells detected in the entire layer or throughout $30^{\circ}$ angular sectors (departing from the lateral side, numbered sectors 1 to 12 , clockwise), in both the GL and GCL. Values were given as $\mathrm{BrdU}^{+}$cell density (number of positive cells per millimeter squared) for 15 and $30 \mathrm{~d}$ data, or normalized cell density (relative to control $30 \mathrm{~d}$ values) for behaviorally tested animals. For Zif268 data, values were given as normalized cell density with respect to $\mathrm{MO}$ (in each case relative to the total number of $\mathrm{Zif} 268^{+}$cells per section).

\section{Results}

\section{Olfactory discrimination learning in MOR23 mice}

To investigate whether an associative learning task could affect newborn cell survival in the $\mathrm{OB}$, we used a transgenic strain in which coexpression of the odorant receptor MOR23 with GFP labels two glomeruli per bulb (Fig. 1A) (Vassalli et al., 2002). To first evaluate the survival rate of adult-born bulbar interneurons in MOR23 mice, newborn cells were labeled with BrdU and their numbers in the OB quantified 15 and $30 \mathrm{~d}$ later. We found that newborn cell density declined along that period in the GL and GCL (Fig. 1C,D). To check for neuronal phenotype, analysis of the coexpression of BrdU with the neuronal marker NeuN was performed using confocal microscopy. The percentage of $\mathrm{BrdU}^{+}$ cells that colabeled for the neuronal marker did not differ between the two time points in both layers (GL, $p=0.36$; GCL, $p=$ 0.11 , Student's $t$ test) (Fig. $1 E, F)$. Thirty days after BrdU injections, $>95 \%$ of newborn cells in the GCL and $65 \%$ in the GL were mature neurons, indicating that the decrease found between 15 and $30 \mathrm{~d}$ concerns mainly the neuronal population.

In these mice, the labeled glomeruli potentially respond to lyral, a MOR23 ligand previously identified in vitro (Touhara et al., 1999; Grosmaitre et al., 2006). We designed a behavioral protocol such that mice could learn to discriminate lyral from another olfactory cue (i.e., acetophenone) activating distinct glomeruli (Bozza et al., 2002) quite distant from the MOR23-tagged ones (Vassalli et al., 2002). Three weeks before starting the training protocol, animals received BrdU to unambiguously evaluate the impact of learning on newborn cell survival (Fig. $2 A$ ). These time points were chosen because of the following: (1) most threeweek-old newborn neurons are fully integrated into bulbar circuits (Belluzzi et al., 2003; Carleton et al., 2003), (2) they are the most responsive to odors at that age (Magavi et al., 2005), and (3) their survival tightly depends on sensory activity occurring during a critical period from 2 to 4 weeks (Yamaguchi and Mori, 2005).

In our behavioral design, the reinforcement was always associated with lyral (paired group), or randomly assigned to either lyral or acetophenone (unpaired group). Mice from the paired group gradually improved their performance throughout the discrimination learning period to reach $85 \%$ success at day 6 (Fig. $2 B)$. In contrast, the unpaired group remained at chance levels throughout the same period, indicating that only odorant cues were used to locate the reward (group, $F_{(1,29)}=56.21, p<0.0001$; session, $F_{(5,145)}=2.77, p=0.020$; group by session, $F_{(5,145)}=$ $2.41, p=0.039)$. Note that a trend toward better performance of paired versus unpaired subjects appeared as early as day 1, although performances in the two groups were initially identical (supplemental Fig. 1, available at www.jneurosci.org as supple- 
mental material). Spontaneous exploration of each odorant was similar (Fig. 2C) ( $p=0.47$, Student's $t$ test), demonstrating that acquisition of the association between food reward and lyral did not result from a preference bias toward lyral. Finally, both groups were similarly exposed to each olfactory cue during discrimination training, because their levels of alternations (paired, $38.81 \pm 5.16$; unpaired, $32.13 \pm 2.80 ; p=0.27$, Student's $t$ test) and odorant sources visits (Fig. 2D) $(p=0.32$, Student's $t$ test $)$ were indistinguishable.

\section{Learning increases adult-generated cell survival}

Two days after discrimination training, OBs were processed for GFP and BrdU staining (Fig. 3). The medial MOR23-GFP glomerulus was used as a reliable anatomical landmark to compare newborn cell distribution in a local network relevant to the behavioral training. We used a quantitative image analysis on coronal sections containing the MOR23 glomeruli (Fig. $3 A, B)$. A significant increase in the density of $\mathrm{BrdU}^{+}$cells was found in the GL and GCL of the paired group as compared with control mice (Fig. 3C,D), indicative of enhanced cell survival. Comparison between paired and unpaired groups also revealed a higher survival rate in the GL $(p=0.051$; Fisher's PLSD test after ANOVA) (Fig. $3 C$ ) and GCL $(p<0.05)$ (Fig. 3D) of paired animals. No significant differences were found between control and unpaired groups $(p>0.05$, Fisher's PLSD test after ANOVA), and food deprivation, social isolation, and handling per se did not affect neurogenesis (supplemental Fig. 2, available at www.jneurosci.org as supplemental material).

When the spatial distribution of the newcomers was analyzed, we noted that the increase in $\mathrm{BrdU}^{+}$cell density in the paired group was distributed throughout all angular sectors (in the GCL group, $F_{(2,35)}=5.49, p=0.008$; sector, $F_{(11,385)}=$ $6.34, p<0.0001$; group by sector $F_{(22,385)}=$ 0.91, not significant) (Fig. 3E). However, significant differences between paired and unpaired groups were observed only in particular laterodorsal portions of the $\mathrm{OB}$ (for representative images, see supplemental Fig. 3A, available at www.jneurosci. org as supplemental material). Interestingly, control and unpaired distributions were not significantly different $[p>0.05$, Fisher's PLSD test after repeated-measures ANOVA (r-mANOVA)], indicating that the mere activation of sensory inputs was insufficient to influence spatial patterns of

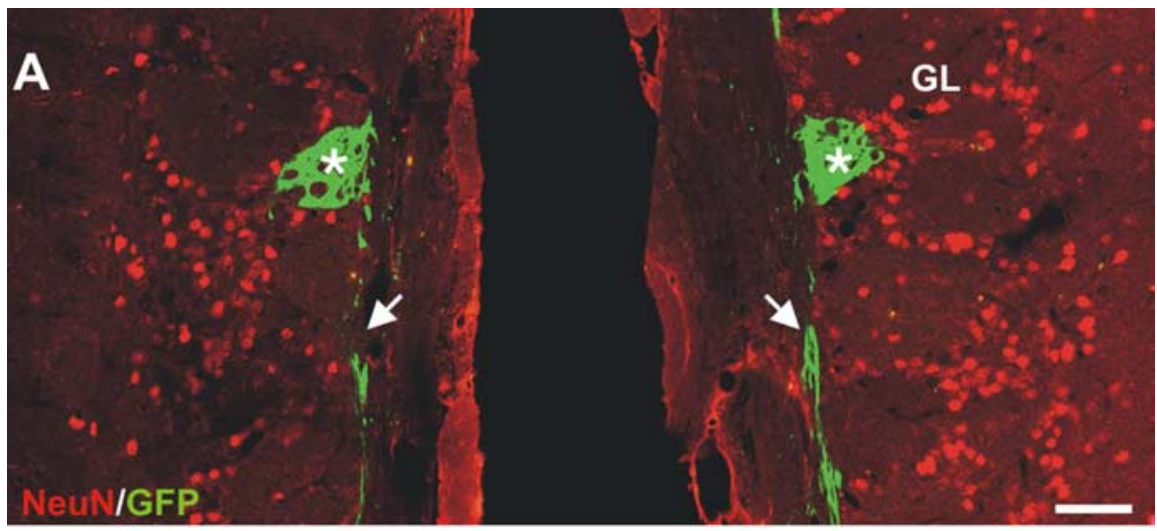

B

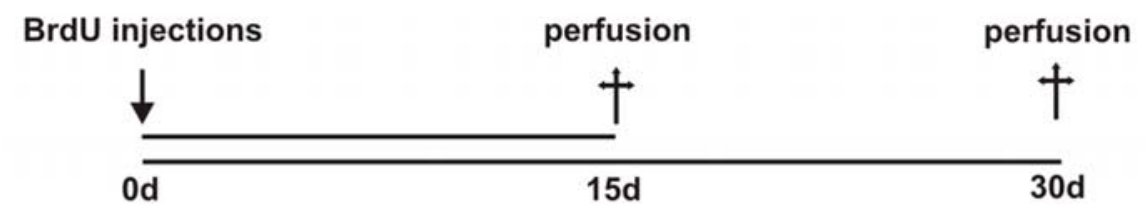

C

D
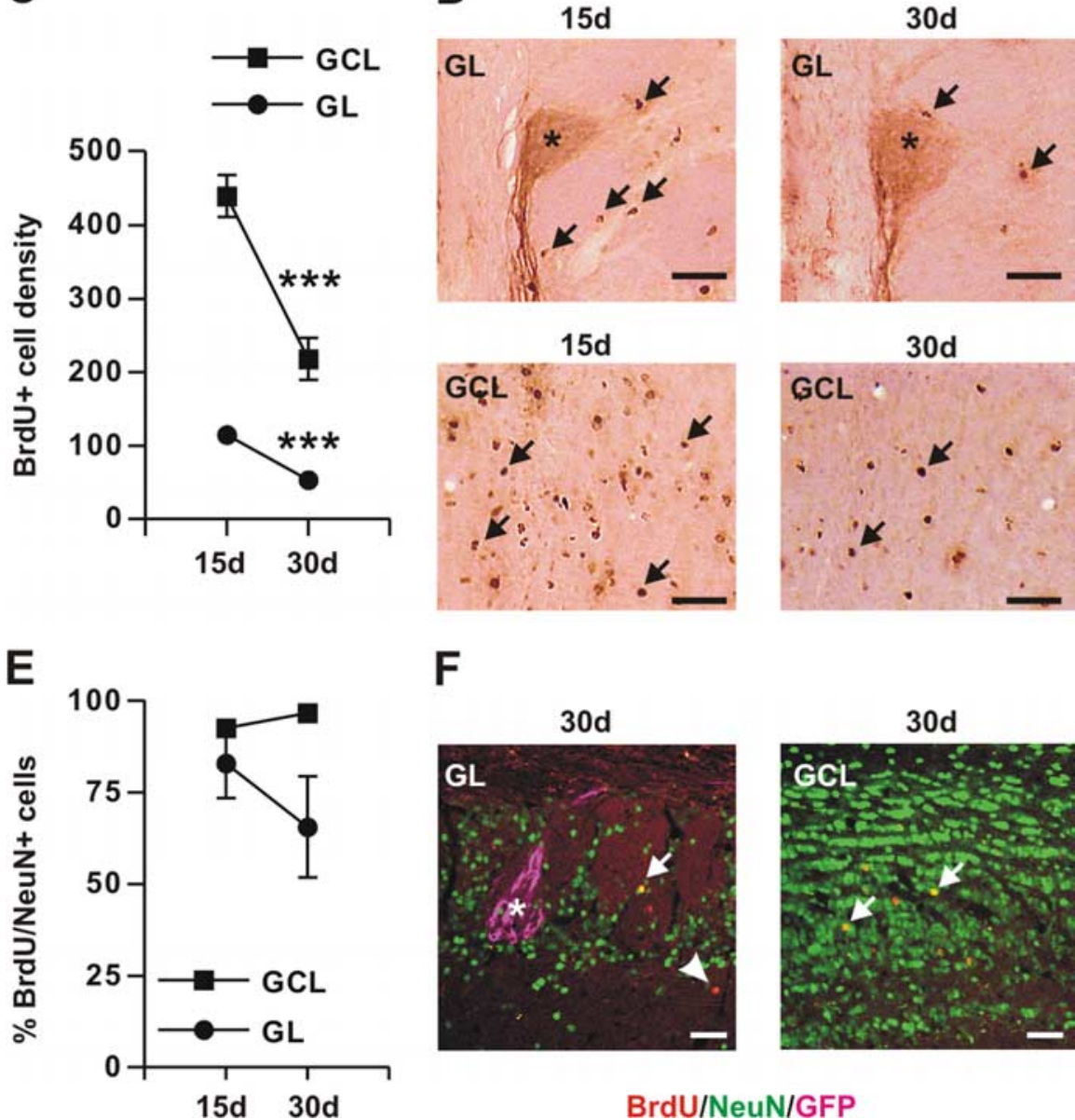

$\mathbf{F}$
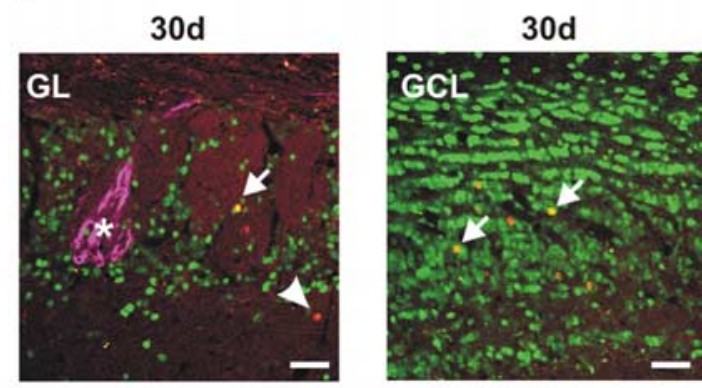

\section{BrdU/NeuN/GFP}

Figure 1. Decline in newborn $\mathrm{OB}$ cells between 15 and $30 \mathrm{~d}$ after BrdU administration. $A, A$ confocal microscope image of a coronal section through the $\mathrm{OB}$ of a 2-month-old MOR23-IRES (internal ribosome entry site)-tau-GFP mouse. Axon terminals of the $\mathrm{GFP}^{+}$(MOR23) sensory neurons converge in two medial glomeruli (asterisks). Arrows indicate axons reaching the $0 \mathrm{~B}$. Neurons were identified with anti-NeuN staining (red). $\boldsymbol{B}$, New cells were labeled with BrdU and their survival evaluated either 15 or $30 \mathrm{~d}$ after intraperitoneal injections. C, BrdU ${ }^{+}$cell density significantly decreased between 15 and $30 \mathrm{~d}$, in both GL and GCL. ${ }^{* * *} p<0.05$, Student's $t$ test $(n=8-9)$. D, Representative images showing BrdU ${ }^{+}$cells in the $\mathrm{GL}$ and GCL at 15 and $30 \mathrm{~d}$. Asterisk indicates the MOR23-GFP medial glomerulus; arrows point to BrdU ${ }^{+}$cells. $E$, Percentage of double-labeled BrdU/NeuN ${ }^{+}$cells 
A

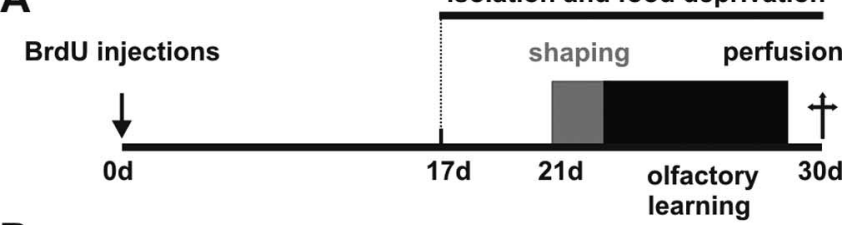

B
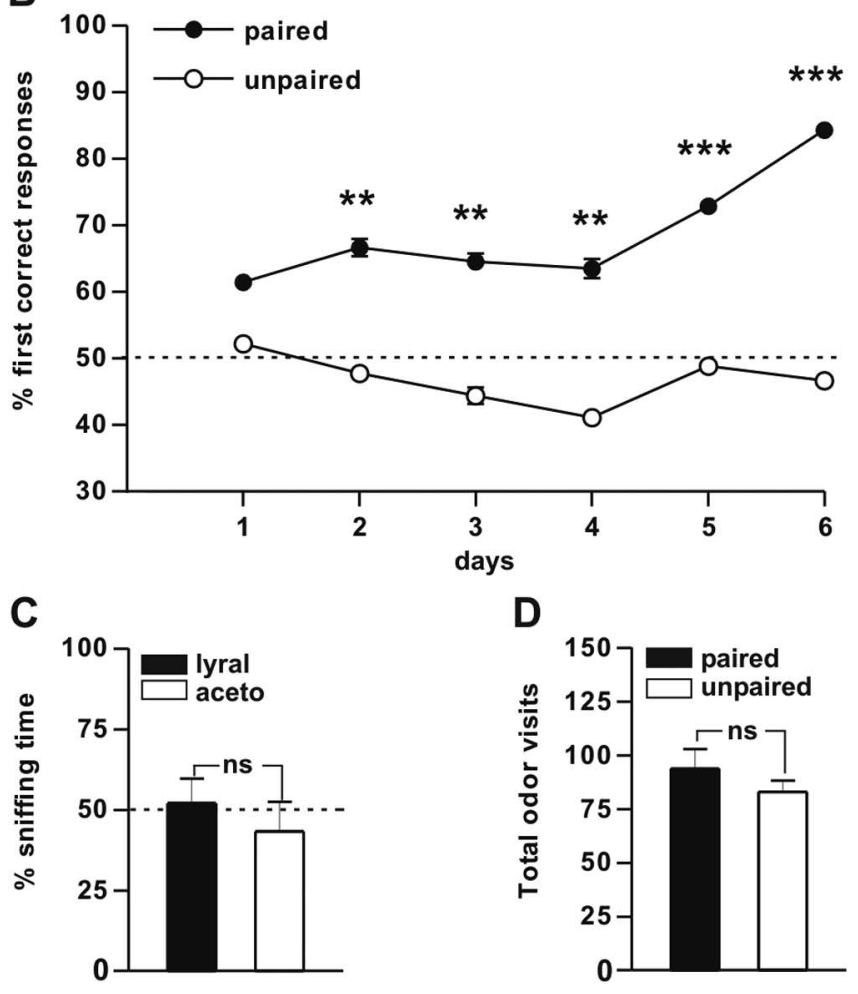

Figure 2. Olfactory discrimination learning between lyral and acetophenone in M0R23 mice. $\boldsymbol{A}$, Experimental design for this study. $\boldsymbol{B}$, Olfactory discrimination learning. Values are expressed as percentage of first correct responses during a daily session. ${ }^{* *} p<0.01$; ${ }^{* * *} p<$ 0.001 between paired/unpaired groups with Bonferroni's test after r-mANOVA ( $n=15-16)$. $C$, Spontaneous exploration of odorants used in the learning task was not significantly different. Data are expressed as the percentage of lyral (pure) and acetophenone $\left(10^{-3}\right)$ sniffing time normalized to the total sniffing time $(n=7-8)$. $\boldsymbol{D}$, Total exposure to the olfactory cues was similar in both groups. Data are expressed as the total number of visits during the entire training period ( $n=15-16)$. ns, Not significant. Error bars indicate SE.

cell survival. These results demonstrate that olfactory learning increases newborn cell survival, but that the learning-specific effect spreads unevenly throughout the GCL.

To study odor-induced activation in the sectors in which the newborn cell survival was significantly enhanced, we studied the pattern of activity produced by lyral or acetophenone exposure in MOR23-containing sections from naive animals. For this, immediate early gene Zif268 expression mapping has proven useful for the identification of activated zones in a number of brain regions (Greenberg et al., 1986), including the GL, where it reflects the degree of sensory inputs (Inaki et al., 2002). After lyral exposure, the distribution of Zif268 expression peaked in dorsomedial (from sector 5 to 8 ) and ventrolateral (sectors 11 and 12) regions of the $\mathrm{OB}$ (Fig. 3F, for representative images, see supplemental Fig. $3 B$, available at www.jneurosci.org as supplemental material). These maxima were significantly distinct from the ones triggered by acetophenone (sector 4 and from sector 6 to 8 ). We thus conclude that odorant-induced activation maps in MOR23containing $\mathrm{OB}$ sections clearly differ when driven by either lyral or acetophenone (group, $F_{(1,7)}=8.58, p=0.020$; sector, $F_{(11,77)}=$ 8.77, $p<0.0001$; group by sector, $\left.F_{(11,77)}=3.61, p=0.0004\right)$. Surprisingly, the zones activated by both odorants did not show any significant increase in newborn cell survival. In contrast, cell survival in the paired group was higher in areas where only acetophenone-induced activity was most important (i.e., sector 4) or where sensory activation maps induced by the two odorants were the most distinct (sectors 3-5). Learning-enhanced survival might therefore correlate with the patterns of activation produced by odor stimuli. Indeed we found that maps of learninginduced survival (paired/unpaired $\mathrm{BrdU}^{+}$ratio) (Fig. 3G; see also supplemental methods, available at www.jneurosci.org as supplemental material) and acetophenone-specific activation (actophenone/lyral Zif268 + ratio) (Fig. $3 H$, supplemental Fig. 4, available at www.jneurosci.org as supplemental material) showed a significant positive correlation $(r=0.61$ with $p<0.04)$.

\section{Discussion}

Three main conclusions arise from these results. First, olfactory discrimination learning over only $6 \mathrm{~d}$ is enough to significantly increase the survival of adult newborn neurons in the OB. Second, in contrast to previous thinking, the mere activation of sensory inputs is insufficient to regulate adult neurogenesis, at least during this time window. Finally, survival of the newcomers is restricted to circuits that are functionally relevant for the learning task.

Today, the contribution of adult neurogenesis to information processing and learning is a central question. In the olfactory system, adult-born neurons extend new processes and form new synapses within few days (Belluzzi et al., 2003; Carleton et al., 2003). Previous studies attempted to correlate memory performance with levels of neurogenesis: increased newborn cell survival observed after enrichment was associated with improved olfactory memory (Rochefort et al., 2002) whereas olfactory discrimination was reduced when neurogenesis was impaired (Gheusi et al., 2000; Enwere et al., 2004). In turn, the present study demonstrates that olfactory learning increases locally newborn cell survival, suggesting potential functional consequences for olfactory information processing.

The effect of learning was to reduce the degree of newborn neuron elimination that normally occurs through apoptotic mechanisms between 15 and $30 \mathrm{~d}$ (Petreanu and Alvarez-Buylla, 2002; Winner et al., 2002; Giachino et al., 2005; Yamaguchi and Mori, 2005). Surprisingly, we found that this effect was not correlated with regions around the MOR23 glomerulus that are activated by both odorants. In contrast, survival was significantly increased in loci where the activation driven by the nonreinforced cue was highest. It is thus possible that the odor information without reward (i.e., negative information) has a more dominant role for survival of newborn neurons than positive information in a paired-test context. Alternatively, newborn neurons could tend to survive in those sectors where the level of sensory activation produced by different odors are the most distinct. Additional experiments will be required to distinguish between these two possibilities. Particularly interesting is the possibility of (with respect to total BrdU ${ }^{+}$cells) in the GL and GCL $(n=3)$. $\boldsymbol{F}$, Double-labeled cells (arrows) in the GL and GCL 30 d after BrdU injections showing colocalization of BrdU (red) with NeuN (green). Some newborn cells are $\mathrm{NeuN}^{-}$(arrowhead). In the GL, GFP ${ }^{+}$ axon terminals of MOR23-sensory neurons converged in one medial glomerulus (asterisk, pink). Scale bars, $50 \mu \mathrm{m}$. Error bars indicate SE. 
A

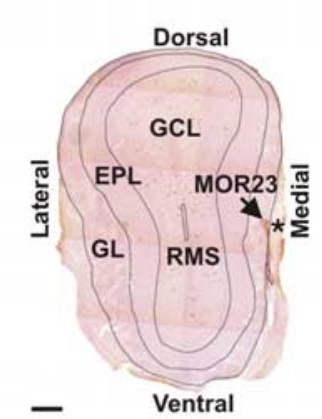

C

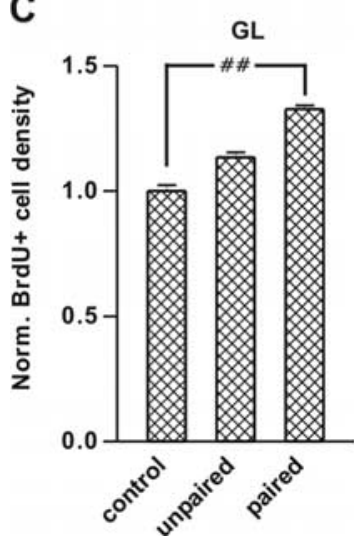

B

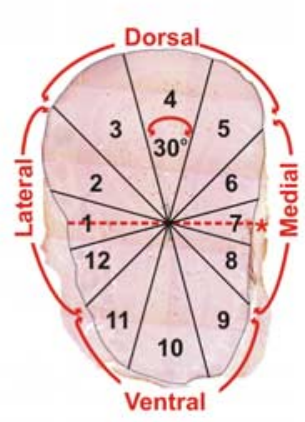

D

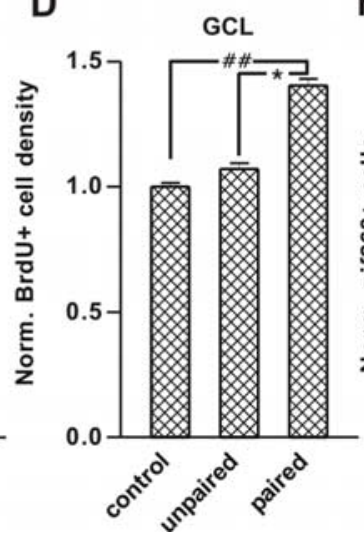

E

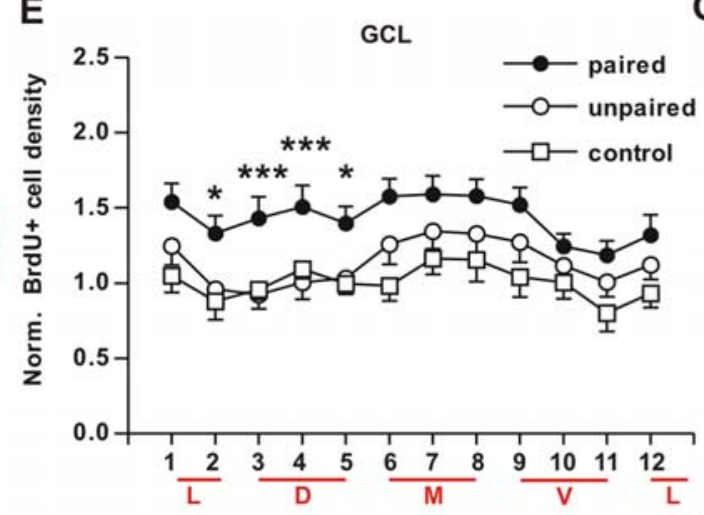

F

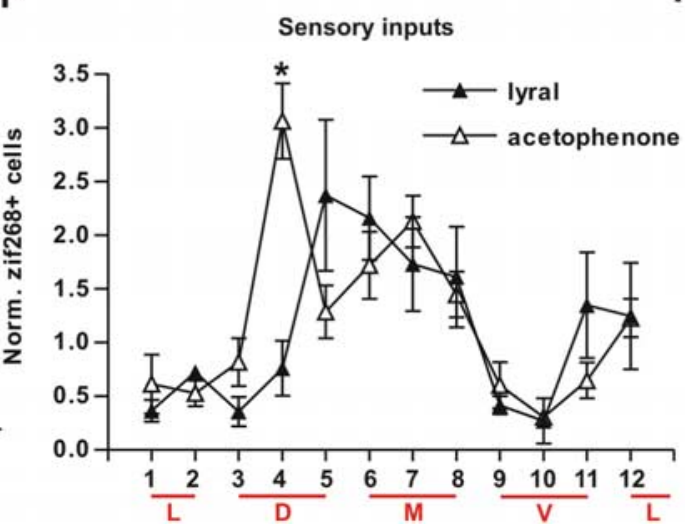

G

Learning-induced survival map

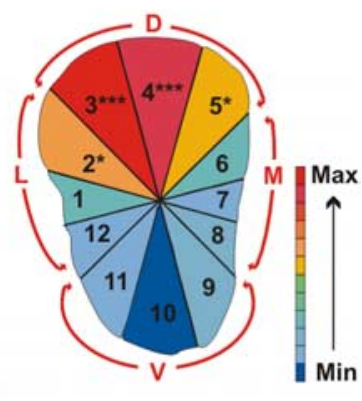

H

Acetophenone-specific activation map

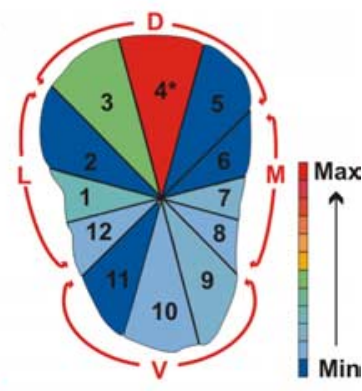

Figure 3. Local increase of newborn cell survival after olfactory discrimination learning. $A, B$, Quantification of BrdU ${ }^{+}$and Zif268 ${ }^{+}$cell distributions, through angular sectors of coronal sections, in the GL and GCL. A, A representative image showing the distinct layers and the medial position of the MOR23 glomerulus. GFP ${ }^{+}$glomeruli were stained by immunohistochemistry with an anti-GFP antibody and VIP substrate as a chromogen (asterisk). $\boldsymbol{B}$, The position of the MOR23 glomerulus was used to define the MOR23 axis (red dotted line) and all subsequent angular sectors. The defined sectors were grouped into four areas related to their location in the 0 B: lateral (sectors 12, 1, and 2), dorsal (sectors 3, 4, and 5), medial (sectors 6, 7, and 8), and ventral (sectors 9, 10, and 11). C, D, $\mathrm{BrdU}^{+}$cell density in the $\mathrm{GL}(\boldsymbol{A})$ and $\mathrm{GCL}(\boldsymbol{B})$ after training. Values were normalized with respect to controls perfused $30 \mathrm{~d}$ after BrdU injections. Discrimination learning significantly increased the total density of BrdU ${ }^{+}$cells when compared with unpaired and control animals in the $\mathrm{GCL}$ and with controls in the $\mathrm{GL} .{ }^{*} p<0.05$ and ${ }^{\# \#} p<0.01$ with Fisher's PLSD test after ANOVA ( $n=9-15$ ). $E$, Distribution of normalized BrdU ${ }^{+}$cell density throughout all angular sectors after discrimination training in GCL. ${ }^{*} p<0.05{ }^{* * *} p<0.001$ with Fisher's PLSD test after r-mANOVA. F, Distribution of normalized sensory inputs driven by odorant cues. Spatial distribution of normalized Zif268 ${ }^{+}$cells throughout the radial axis of coronal $0 B$ sections after lyral (pure) or acetophenone $\left(10^{-3}\right.$ ) exposure. ${ }^{*} p<0.05$ between two odorants with Fisher's PLSD test after r-mANOVA. $\mathbf{G}, \boldsymbol{H}$, Survival of newborn neurons was highest where odor activation maps differed most. $\mathbf{G}$, Color-coded representations showing learning-induced survival maps throughout MOR23-containing sections (supplemental methods and Fig. 4, available at www.jneurosci.org as supplemental material). $\boldsymbol{H}$, A representation similar to that in $\mathbf{G}$ showing the acetophenone-specific activation map. EPL, External plexiform layer; L, lateral; D, dorsal; $M$, medial; $V$, ventral. Scale bar, $200 \mu \mathrm{m}$. Error bars indicate SE.

analyzing $\mathrm{OB}$ regions exclusively activated by lyral in a reversed paired task, when this molecule is used as the non-reinforced odor. Why increase the population of newborn neurons in restricted areas? If it is clear that bulbar interneurons play a key role in synchronizing OB output neurons (Lledo and Lagier, 2006), we still do not know whether the newcomers exert similar or opposite functions. The pair of odorants used in our study was not spontaneously discriminated but was discriminated when the odorants were differentially reinforced. In this context, it is tempting to suggest that adjusting the distribution of newborn neurons in a learning context might enhance the contrast between spatial activation patterns produced by the two odorants. This supports the hypothesis that small differences in glomerular activity can be used to make odorant discrimination as long as animals are subjected to the motivational and experimental consequences of differential reinforcement (Linster et al., 2002). This assumption is also supported by theoretical data showing that activity-dependent survival of new neurons maximizes odor discrimination (Cecchi et al., 2001).

We chose lyral as the reinforced odorant because previous studies have identified this molecule as the ligand for MOR23
(Touhara et al., 1999; Grosmaitre et al., 2006) and acetophenone because it activates glomeruli located in distinct dorsal areas (Bozza et al., 2002; Vassalli et al., 2002). However, we found that acetophenone-induced activation maps were broad, including not only the expected dorsal sectors but also some medial areas of MOR23-containing sections. This observation partially disagrees with previous results showing a restricted intrinsic signal after odorant stimulation, superimposable to the respective glomeruli (Belluscio et al., 2002; but see also maps in http://leonserver.bio. uci.edu/). Moreover, recent evidence suggests that at high concentrations acetophenone induces broad activation in the $\mathrm{OB}$ ( $\mathrm{P}$. Mombaerts, personal communication), supporting the present results. In this context, it is important to consider that glomerular activation spreads also laterally within the OB circuit (Schoppa and Urban, 2003; Lledo and Lagier, 2006) and therefore spatial maps are highly dynamic. Finally, it is noteworthy that the maps we constructed only reflected odor-induced activity at initial learning stages, and might have evolved as the training progressed (Salcedo et al., 2005).

Neural circuits must exhibit activity-dependent plasticity to cope with a changing environment. Our study does not allow any 
conclusion to be drawn concerning the mechanisms mediating the survival effect of olfactory learning. However, the observation that experience shapes neurogenesis poses the question as to the role of neural activity in organizing the spatial distribution of the newcomers. In particular, we still do not know how much of the ongoing neurogenesis is sensitive to the activity of both sensory afferents and feedback centrifugal fibers that contain glutamate, acetylcholine, serotonin, and norepinephrine, acting in a concerted manner at different sites of the OB (Shepherd et al., 2004). Some of these neuromodulators have been implied in the local modulation of dendrodendritic synaptic microcircuits (Shepherd et al., 2004) and in olfactory memory formation (Wilson and Stevenson, 2003). In line with our results, neuromodulators also have been found to regulate adult-born cell survival (Bauer et al., 2003; Mechawar et al., 2004). Thus, an enhanced survival rate could result from the coincidence detection of sensory feedforward and centrifugal feedback inputs to the OB circuit.

To conclude, our results reveal that sensory inputs in a learning context are important to locally control the survival of new neurons in behaviorally relevant networks in the adult $\mathrm{OB}$, indicating that sensory experience shapes $\mathrm{OB}$ microcircuits beyond the simple modulation of existing synaptic connections.

\section{References}

Abrous DN, Koehl M, Le Moal M (2005) Adult neurogenesis: from precursors to network and physiology. Physiol Rev 85:523-569.

Alvarez-Buylla A, Garcia-Verdugo JM (2002) Neurogenesis in adult subventricular zone. J Neurosci 22:629-634.

Bauer S, Moyse E, Jourdan F, Colpaert F, Martel JC, Marien M (2003) Effects of the alpha 2-adrenoreceptor antagonist dexefaroxan on neurogenesis in the olfactory bulb of the adult rat in vivo: selective protection against neuronal death. Neuroscience 117:281-291.

Belluscio L, Lodovichi C, Feinstein P, Mombaerts P, Katz LC (2002) Odorant receptors instruct functional circuitry in the mouse olfactory bulb. Nature 419:296-300.

Belluzzi O, Benedusi M, Ackman J, LoTurco JJ (2003) Electrophysiological differentiation of new neurons in the olfactory bulb. J Neurosci 23:10411-10418.

Bozza T, Feinstein P, Zheng C, Mombaerts P (2002) Odorant receptor expression defines functional units in the mouse olfactory system. J Neurosci 22:3033-3043.

Carleton A, Petreanu LT, Lansford R, Alvarez-Buylla A, Lledo PM (2003) Becoming a new neuron in the adult olfactory bulb. Nat Neurosci 6:507-518.

Cecchi GA, Petreanu LT, Alvarez-Buylla A, Magnasco MO (2001) Unsupervised learning and adaptation in a model of adult neurogenesis. J Comput Neurosci 11:175-182.

Enwere E, Shingo T, Gregg C, Fujikawa H, Ohta S, Weiss S (2004) Aging results in reduced epidermal growth factor receptor signaling, diminished olfactory neurogenesis, and deficits in fine olfactory discrimination. J Neurosci 24:8354-8365.

Gheusi G, Cremer H, McLean H, Chazal G, Vincent JD, Lledo PM (2000) Importance of newly generated neurons in the adult olfactory bulb for odor discrimination. Proc Natl Acad Sci USA 97:1823-1828.

Giachino C, De Marchis S, Giampietro C, Parlato R, Perroteau I, Schutz G, Fasolo A, Peretto P (2005) cAMP response element-binding protein regulates differentiation and survival of newborn neurons in the olfactory bulb. J Neurosci 25:10105-10118.

Greenberg ME, Ziff EB, Greene LA (1986) Stimulation of neuronal acetylcholine receptors induces rapid gene transcription. Science 234:80-83.

Grosmaitre X, Vassalli A, Mombaerts P, Shepherd GM, Ma M (2006) Odorant responses of olfactory sensory neurons expressing the odorant receptor MOR23: a patch clamp analysis in gene-targeted mice. Proc Natl Acad Sci USA 103:1970-1975.

Inaki K, Takahashi YK, Nagayama S, Mori K (2002) Molecular-feature domains with posterodorsal-anteroventral polarity in the symmetrical sensory maps of the mouse olfactory bulb: mapping of odourant-induced Zif268 expression. Eur J Neurosci 15:1563-1574.

Kempermann G, Wiskott L, Gage FH (2004) Functional significance of adult neurogenesis. Curr Opin Neurobiol 14:186-191.

Linster C, Johnson BA, Morse A, Yue E, Leon M (2002) Spontaneous versus reinforced olfactory discriminations. J Neurosci 22:6842-6845.

Lledo PM, Lagier S (2006) Adjusting neurophysiological computations in the adult olfactory bulb. Semin Cell Dev Biol 17:443-453.

Lledo PM, Alonso M, Grubb MS (2006) Adult neurogenesis and functional plasticity in neuronal circuits. Nat Rev Neurosci 7:179-193.

Magavi SS, Mitchell BD, Szentirmai O, Carter BS, Macklis JD (2005) Adultborn and preexisting olfactory granule neurons undergo distinct experience-dependent modifications of their olfactory responses in vivo. J Neurosci 25:10729-10739.

Mechawar N, Saghatelyan A, Grailhe R, Scoriels L, Gheusi G, Gabellec M-M, Lledo PM, Changeux J-P (2004) Nicotinic receptors regulate the survival of newborn neurons in the adult olfactory bulb. Proc Natl Acad Sci USA 101:9822-9826.

Ming GL, Song H (2005) Adult neurogenesis in the mammalian central nervous system. Annu Rev Neurosci 28:223-250.

Olivo-Marin JC (2002) Extraction of spots in biological images using multiscale products. Pattern Recognit 35:1989-1996.

Petreanu L, Alvarez-Buylla A (2002) Maturation and death of adult-born olfactory bulb granule neurons: role of olfaction. J Neurosci 22:6106-6113.

Rochefort C, Gheusi G, Vincent JD, Lledo PM (2002) Enriched odor exposure increases the number of newborn neurons in the adult olfactory bulb and improves odor memory. J Neurosci 22:2679-2689.

Salcedo E, Zhang C, Kronberg E, Restrepo D (2005) Analysis of traininginduced changes in ethyl acetate odor maps using a new computational tool to map the glomerular layer of the olfactory bulb. Chem Senses 30:615-626.

Schoppa NE, Urban NN (2003) Dendritic processing within olfactory bulb circuits. Trends Neurosci 26:501-506.

Shepherd GM, Chen WR, Greer CA (2004) Olfactory bulb. In: The synaptic organization of the brain (Shepherd GM, ed), pp 165-216. Oxford: Oxford UP.

Touhara K, Sengoku S, Inaki K, Tsuboi A, Hirono J, Sato T, Sakano H, Haga T (1999) Functional identification and reconstitution of an odorant receptor in single olfactory neurons. Proc Natl Acad Sci USA 96:4040-4045.

Vassalli A, Rothman A, Feinstein P, Zapotocky M, Mombaerts P (2002) Minigenes impart odorant receptor-specific axon guidance in the olfactory bulb. Neuron 35:681-696.

Wilson DA, Stevenson RJ (2003) The fundamental role of memory in olfactory perception. Trends Neurosci 26:243-247.

Winner B, Cooper-Kuhn CM, Aigner R, Winkler J, Kuhn HG (2002) Longterm survival and cell death of newly generated neurons in the adult rat olfactory bulb. Eur J Neurosci 16:1681-1689.

Yamaguchi M, Mori K (2005) Critical period for sensory experiencedependent survival of newly generated granule cells in the adult mouse olfactory bulb. Proc Natl Acad Sci USA 102:9697-9702. 